\title{
Does Perpetrating Violence Damage Mental Health? Differences Between Forcibly Recruited and Voluntary Combatants in DR Congo
}

\author{
Tobias Hecker, ${ }^{1,2}$ Katharin Hermenau, ${ }^{1,2}$ Anna Maedl, ${ }^{2}$ Harald Hinkel, ${ }^{3}$ Maggie Schauer, ${ }^{1,2}$ \\ and Thomas Elbert ${ }^{1,2}$ \\ ${ }^{1}$ Department of Psychology, University of Konstanz, Konstanz, Germany \\ ${ }^{2}$ vivo international, www.vivo.org \\ ${ }^{3}$ Kigali, Rwanda
}

\begin{abstract}
As a consequence of the ongoing conflict in the Democratic Republic of the Congo (DRC), combatants are constantly involved in various forms of violence. Findings concerning the impact of perpetrating violence on mental health are contradictory, ranging from increasing to buffering the risk for mental ill health. The present study investigated the impact of perpetrating violence on mental health. In total, 204 forcibly recruited and voluntary male combatants (mean age $=24.61$ years) from different armed groups in the eastern DRC took part in the study. In a semistructured interview, respondents were questioned about appetitive aggression and posttraumatic stress disorder (PTSD) as well as self-experienced violence and self-perpetrated violent offending. A multivariate analysis of variance $\left(\eta^{2}=.23\right)$ revealed that voluntary combatants perpetrated more violent acts $\left(\eta^{2}=.06\right)$ and showed higher appetitive aggression $\left.\eta^{2}=.03\right)$. A moderated multiple regression analysis $\left(R^{2}=.20\right)$ showed that perpetrating violence was positively related to PTSD in forcibly recruited combatants, but not in voluntary combatants. Thus, perpetrating violence may not necessarily qualify as a traumatic stressor. Further studies might consider assessing the combatant's perception of committing violent acts.
\end{abstract}

The eastern Congo has been trapped in an ongoing cycle of war and violence for more than two decades. Civilians suffer on a large scale from the consequences of violence (Guy, 2009; Maedl, 2011). The detrimental mental effects of exposure to violence are, however, not only common for civilian victims, but also for soldiers and combatants. Prior research has consistently shown that exposure to violence, including organized violence, enhances the risk of mental ill health such as trauma-related

This research was supported by the NGO vivo international and by the Deutsche Forschungsgemeinschaft. We are grateful to all the former combatants for their readiness to participate and willingness to talk about often intimate and painful subjects. We thank our local staff, Roger Buhendwa Zashurwa, Ben Ombeni Cigolo, and Flory Barhimanya Kahisa for translating the interviews, their commitment to our work, and their empathy with participants. Moreover, we thank the staff of the training center Equipe d' Education et d'Encadrement des Traumatisés de Nyiragongo in Goma and the staff of the demobilization camp of the United Nations in Goma for all their help. We are grateful to James Moran who critically reviewed the manuscript. Last but not least, we thank Heike Riedke for her support with data collection and logistics. We profited a lot from her extensive knowledge of the Great Lakes Region.

Correspondence concerning this article should be addressed to Tobias Hecker, Department of Psychology, University of Konstanz, Box 23/25, 78457 Konstanz, Germany. E-mail: tobias.hecker@uni-konstanz.de illnesses, depression, or substance abuse (Amone-P'Olak, Garnefski, \& Kraaij, 2007; Catani, Jacob, Schauer, Kohila, \& Neuner, 2008; Hermenau et al., 2011; Neuner et al., 2004; Odenwald et al., 2007). Additionally, combatants perpetrate violent acts, which may also have an impact on their mental health. In a number of studies, researchers rated perpetrating violent acts (e.g., killing or raping) as traumatic events (Bayer, Klasen, \& Adam, 2007; Vinck, Pham, Stover, \& Weinstein, 2007). Following the Diagnostic and Statistical Manual of Mental Disorders (4th ed., text rev.; DSM-IV-TR; American Psychiatric Association, 2000), a life event is classified as traumatic if it produces feelings of helplessness, horror, or massive fear. Perpetrating violence (e.g., torturing or raping), however, might not necessarily result in a fearful or horrified response and is not always linked to forms of helplessness.

MacNair $(2001,2002)$ concluded from studies with veterans that perpetrating violence (e.g., killing) leads to enhanced risk for posttraumatic stress disorder (PTSD). Hence, she suggested the term perpetrator-induced traumatic stress. In contrast, Pfeiffer and Elbert (2011) showed a negative relation between the number of years as a member of rebel forces and PTSD symptoms. Elbert, Weierstall, and Schauer (2010) reported that many soldiers and combatants described perpetrating violent acts as fascinating, appealing, and exciting. This phenomenon of appetitive aggression has only recently begun 
to receive attention. A number of studies with former child soldiers in Uganda (Weierstall, Schalinski, Crombach, Hecker, \& Elbert, 2012) and genocide perpetrators in Rwanda (Weierstall, Schaal, Schalinski, Dusingizemungu, \& Elbert, 2011) have suggested that appetitive aggression could prevent trauma-related illnesses. According to Elbert et al. (2010), however, the effects of traumatic experiences are cumulative and once the number of traumatic experiences exceeds a certain threshold, then the buffering effect of higher appetitive aggression is no longer effective, though the range of the threshold is not yet precisely known. Two studies from the DRC found that combatants who report high levels of appetitive aggression are characterized by having perpetrated high numbers of violent acts as well as having joined on their own account and as children (Hecker, Hermenau, Maedl, Elbert, \& Schauer, 2012; Weierstall, van der Haer, Banholzer, \& Elbert, 2012).

These contradictory findings concerning the impact of perpetrating violent acts on the mental health of combatants in the eastern Congo were tested in the present study. We hypothesized that the impact of perpetrating violent acts on mental health varies between voluntarily and forcibly recruited combatants. We predicted that forcibly recruited combatants are more often forced to perpetrate violence against their will. Consequently, we hypothesized a more negative impact on their mental health.

The ongoing conflict in the eastern DRC includes foreign armed groups, several local militias, and the Congolese Government Army (Romkema, 2007). Most armed groups in the province of North Kivu recruit a high number of combatants by force. Others, however, volunteer for duty. Reasons for joining vary from seeking a better life to defending the family and ethnic group (Coalition to Stop the Use of Child Soldiers, 2010; Romkema, 2007). Although the decision to join is in some cases the result of limited and equally harsh choices in a resourcepoor region of instability (Guy, 2009; Schauer \& Elbert, 2010), voluntary combatants might feel more in control of their lives and might perceive the armed group as less threatening than forcibly recruited combatants would (Hecker et al., 2012; Hermenau, Hecker, Maedl, Schauer, \& Elbert, 2012).

The present study investigated the impact of perpetrating violent acts on the perpetrator's mental health more closely. The sample consisted of former forcibly recruited and voluntary combatants from different armed groups in the eastern DRC. As the Congolese Government Army (FARDC) is also accused of atrocities against civilians, including forcibly recruiting child soldiers (Davis \& Hayner, 2009), the present study treated the FARDC in its analysis as a local armed group.

Forcibly recruited and voluntary combatants were compared concerning exposure to and perpetration of violent acts, as well as concerning PTSD symptom severity and appetitive aggression. Furthermore, the relationship between PTSD symptom severity and exposure to violence and perpetrated violent acts in both groups was investigated. Possible confounding factors (e.g., age, country of origin, or length of time with armed group) were examined. Furthermore, we examined whether combatants joined foreign armed groups or local militia groups because foreign armed groups were more likely to forcibly recruit combatants, whereas many combatants from local militia groups volunteered for duty. As children growing up in a violent environment often suffer from mental health problems (Hermenau et al., 2012; Schauer \& Elbert, 2010; Waller, 2006), the present study also examined the influence of being recruited before the age of 15 years.

We hypothesized that voluntary combatants perpetrated more violence and perceived violence intrinsically as more fascinating and appealing than forcibly recruited combatants. Hence, they would show higher levels of appetitive aggression. Furthermore, we predicted that self-experienced violence is closely related to PTSD symptom severity. The correlation between perpetrated violent acts and PTSD symptom severity might depend on whether the combatants were recruited voluntarily or forcibly. Therefore, we predicted that the number of perpetrated violent acts would correlate positively with PTSD symptom severity only in forcibly recruited combatants. In voluntary combatants, we predicted that only self-experienced violence would correlate positively with PTSD symptom severity.

\section{Method}

\section{Participants and Procedure}

Two hundred twenty-four interviews were conducted. Only combatants who reported combat experience were included in the analyses. Additionally, eight interviews could not be completed due to the short stay in the demobilization camp. All eight interviews were excluded from the analyses involving the Appetitive Aggression Scale resulting in a sample of $n=202$. For all other analyses only six incomplete interviews had to be excluded resulting in a sample of $n=204$. All participants $(n=204)$ were male reporting a mean age of 24.61 years. Participants belonged to a variety of armed groups and forces. In total, $43 \%(n=91)$ were former members of the foreign armed group Forces Démocratiques pour la Libération du Rwanda (FDLR) and $57 \%(N=119)$ of local armed groups including different Mai-Mai groups, Congrés National pour la Défense du Peuple (CNDP), or the Congolese Government Army (FARDC).

To compare forcibly recruited and voluntary combatants, we divided the sample into two subgroups: 97 combatants reported that they were physically forced to join an armed group; 107 combatants reported that they volunteered to join. In this armed conflict, which has been a part of the people's everyday lives in the eastern Congo for more than two decades, the boundaries between forcible and voluntary recruitment, however, were sometimes blurred. For example, a child may "voluntarily" join the army because his village is always under attack and he just wants to defend himself or his village. In such cases we counted the individual combatant's subjective perception of his recruitment. Table 1 shows demographic characteristics of forcibly recruited and voluntary combatants.

Four clinical psychologists and one Western-trained nurse interviewed all participants with the help of three interpreters, 
Table 1

Demographic Characteristics of Forcibly Recruited and Voluntary Combatants

\begin{tabular}{|c|c|c|c|c|c|}
\hline \multirow[b]{2}{*}{ Variable } & \multicolumn{2}{|c|}{$\begin{array}{l}\text { Forcibly recruited } \\
\qquad(n=97)\end{array}$} & \multicolumn{2}{|c|}{$\begin{array}{l}\text { Voluntary } \\
(n=105)\end{array}$} & \multirow[b]{2}{*}{$F$} \\
\hline & $M$ or $n$ & $S D$ or $\%$ & $M$ or $n$ & $S D$ or $\%$ & \\
\hline Age & 23.18 & 6.37 & 25.72 & 7.45 & $6.27 *$ \\
\hline Years with armed group & 5.53 & 4.20 & 8.02 & 5.75 & $13.58 * * *$ \\
\hline Country of origin & & & & & $4.55 *$ \\
\hline DRC & 80 & 82 & 73 & 68 & \\
\hline Rwanda & 18 & 18 & 35 & 32 & \\
\hline Joined as child & & & & & 0.07 \\
\hline$<15$ years & 37 & 38 & 43 & 40 & \\
\hline$>15$ years & 61 & 62 & 65 & 60 & \\
\hline Group membership & & & & & $6.99 * *$ \\
\hline Local & 48 & 49 & 69 & 64 & \\
\hline Foreign & 50 & 51 & 39 & 36 & \\
\hline Experienced violence types & 4.37 & 1.18 & 4.19 & 1.04 & 0.21 \\
\hline Perpetrated violence types & 4.70 & 2.06 & 5.17 & 1.70 & $11.76^{* *}$ \\
\hline AAS total & 20.87 & 13.59 & 27.69 & 13.70 & $5.05 *$ \\
\hline PSS-I total & 11.18 & 9.14 & 9.30 & 8.82 & 3.17 \\
\hline
\end{tabular}

Note. $F=$ test statistics based on Roy-Bargmann stepdown analysis. DRC = Democratic Republic of Congo; AAS = Appetitive Aggression Scale; PSS-I = Posttraumatic Stress Disorder Symptom Scale Interview.

$* p<.05 . * * p<.01 . * * *<<.001$.

who had all been trained in the concepts of mental disorders and aggression. Semistructured interviews were carried out in Kiswahili, Kinyarwanda, or Lingala. The interviewers had standardized the form of assessment by practicing in joint interviews to achieve high interrater reliability. The translation was discussed in great detail to guarantee a precise translation.

All interviews were conducted between March and May 2011 in Goma, in the province of North Kivu in the eastern Congo. In total, $72 \%(n=152)$ of the interviews took place at the demobilization camp of the United Nations, 27\% $(n=56)$ were conducted at a training center for war-affected youth, and $1 \%$ at the military detention facility. The demobilization camp is a transition camp for all combatants who leave any armed group in the province of North Kivu and report to the United Nations. We were able to interview all combatants who passed through this demobilization camp during the time of assessment. No ex-combatant refused participation. Participants, however, stayed only between 20 and 72 hours in the demobilization camp before being sent to other places. In eight cases, this led to the termination of the interview. In the training center, a Congolese nongovernmental nonprofit organization offered a 1-year vocational training in different manual trades to former child soldiers and ex-combatants. We interviewed all former child soldiers and ex-combatants who were enrolled in the program. Not a single case refused participation. One interviewer and one translator interviewed all interviewees individually in a calm setting. The interview took, on average, 1.5 hours.
The Ethical Review Board of the University of Konstanz approved the study, and the United Nations and the respective Congolese nongovernmental nonprofit organization allowed us to interview all participants enrolled in their program. All participants gave their informed consent orally. In addition to the oral consent of the participants, we asked the respective institutions for permission to interview underaged child soldiers, as their caregivers were not available. Participants received financial compensation of about US \$2.

\section{Measures}

All instruments were administered as an interview. The first part of the interview consisted of sociodemographic information (e.g., place and year of birth as well as educational background). The former combatants were interviewed about their military career (e.g., how they were recruited, length of service, and their highest rank).

Exposure to different types of violence over the combatant's entire lifetime was assessed using a checklist of 30 war- and non-war-related potentially traumatic events (e.g., assault by weapon, rape, life-threatening accidents), which also included events from the checklist of the Posttraumatic Stress Diagnostic Scale (Foa, Cashman, Jaycox, \& Perry, 1997). The checklist that we used was a version of a previously published checklist (Neuner et al., 2004) that we adapted to fit the Congolese cultural context. This checklist showed a high test-retest reliability $(r=$ $.73, p<.001)$ and significant accordance with the CIDI Event 
List (Ertl et al., 2010) in a study with former child soldiers in Uganda. The number of times a specific event had been experienced was not assessed, as we suggest that distorted memory in PTSD renders this measure unreliable (Elbert \& Schauer, 2002; Kolassa \& Elbert, 2007; McNally, 2006). For the analyses, we further distinguished between the number of self-experienced violence types (range $=0-7$; e.g., being physically or sexually assaulted) and the number of perpetrated violence types (range $=0-9$ ), for example, assaulting someone else physically or sexually.

PTSD symptom severity was determined by using the PTSD Symptom Scale-Interview (PSS-I; Foa, Riggs, Dancu, \& Rothbaum, 1993). The PSS-I assesses the 17 DSM-IV symptom criteria for PTSD and refers to symptoms experienced in the previous month. Each of the items was answered on a 4-point scale ranging from $0=$ not at all/only one time to $3=$ five or more times per week/almost always. The PSS-I showed good psychometric properties and is widely used to diagnose PTSD (Foa \& Tolin, 2000; Foa et al., 1993). A PTSD severity score (range $=0-51$ ) was computed by adding all symptom scores. In the present study, Cronbach's $\alpha$ coefficient was .90 .

Appetitive aggression was assessed with the Appetitive Aggression Scale (AAS; Weierstall \& Elbert, 2011), which has been validated with over 1,600 ex-combatants and proven its good psychometric properties in comparable samples in Uganda (Weierstall et al., 2012), Rwanda (Weierstall et al., 2011), and the DRC (Hecker et al., 2012). The AAS consists of 15 items regarding the perception of violence or appetitive aggression (e.g., "Is it exciting for you if you make an opponent really suffer?," "Once fighting has started do you get carried away by the violence?," or "Is fighting the only thing you want to do in life?"). Participants rated how much they personally agreed with a given statement on a 5-point Likert scale ranging from $0=$ disagree to $4=$ agree. The items were based on the definition of the instrumental aggression subtype according to Vitiello and Stoff (1997) and the International Classification of Diseases-10 addiction criteria (ICD-10; World Health Organization, 2008). Further items were compiled on the basis of interviews with child soldiers about the appetitive experience of aggression and violence (Elbert et al., 2010). In the validation study (Weierstall \& Elbert, 2011), the AAS showed good psychometric properties. Cronbach's $\alpha$ coefficient of the sum score was .85 and in a principal-axis factoring analysis all items loaded statistically significant onto a single factor accounting for $32 \%$ of the total variance. Moreover, further analyses revealed that the scale measures a distinct construct of human aggression (for further details see Weierstall \& Elbert, 2011) For the analysis a sum score of all 15 items was computed. It ranged from 0 to 60 . In the present study, Cronbach's $\alpha$ coefficient was .89 .

\section{Data Analysis}

A multivariate analysis of variance (MANOVA) was conducted to compare forcibly recruited and voluntary combatants in their reported number of self-experienced violence types, number of perpetrated violence types, and their PSS-I score, as well as their AAS score. The confounding variables age, years with armed group, group membership (foreign: 0; local: 1), country of origin (Rwanda: 0; DRC: 1), and joining as a child $(\geq 15: 0 ;<15: 1)$ were entered into the model. No variable deviated significantly from normal distribution. Neither univariate nor multivariate outliers could be identified, and variancecovariance matrices showed homogeneity. Subsequently, a Roy-Bargmann stepdown analysis (Tabachnick \& Fidell, 2006) was performed to investigate the contribution of each dependent variable.

A moderated sequential multiple regression analysis was conducted to investigate the prediction of the PSS-I score by the number of experienced and perpetrated violence types. Type of recruitment was included in the analysis. It was dummy-coded with 0 for forcibly recruited and 1 for voluntary combatants. To mitigate multicollinearity, the predictor variables were meancentered for calculations of interaction terms (Kleinbaum, Kupper, Nizam, \& Muller, 2008). The regression analysis included the same confounding variables mentioned above. In the first step, the regression model only included the control variables. In the second step, the main effects of type of recruitment, number of self-experienced violence types, and the number of perpetrated violence types were added to the model. The third step consisted of two-way interactions between type of recruitment and both number of self-experienced and perpetrated violence types. In the last step, the three-way interaction was added to the regression model. All regression models fulfilled the necessary quality criteria for linear regression analyses. The residuals did not deviate significantly from normality, linearity, and homoscedasticity. Neither univariate nor multivariate outliers could be identified. The maximum variance inflation factor did not exceed 3.4. Hence, we did not need to take multicollinearity into account. All analyses used a two-tailed $\alpha=.05$. Our metric for a small effect size was $\eta^{2}=.01$, for a medium effect, $\eta^{2}=.06$; and for a large effect; $\eta^{2}=.14$.

\section{Results}

\section{Differences Between Forcibly Recruited and Voluntary Combatants}

Results of the MANOVA indicated that, according to Wilks's criterion, at least one mean of the dependent variables, including AAS score, number of perpetrated violence types, PSS-I score and number of self-experienced violence types, differed between forcibly recruited and voluntary combatants, $F(9,192)$ $=6.47, p<.001, \eta^{2}=.23$

With differences due to confounding variables already entered, both the mean of the number of perpetrated violence types and of the AAS score differed significantly between the two groups (see Table 1). Voluntary combatants reported more perpetrated violence types than forcibly recruited combatants with a medium effect of $\eta^{2}=.06$. The same was true for the AAS score, but with a small effect of $\eta^{2}=.03$. The mean 
Table 2

Multiple Regression Analysis for PSS-I Score

\begin{tabular}{|c|c|c|c|c|}
\hline \multirow[b]{2}{*}{ Predictor variables } & \multicolumn{4}{|c|}{ PSS-I score } \\
\hline & $\mathrm{B}$ & SE of B & $\beta$ & $t$ \\
\hline \multicolumn{5}{|l|}{ Step 1} \\
\hline Age & -0.45 & 0.15 & -.35 & $-3.07 *$ \\
\hline Joining as a child & -0.68 & 1.69 & -.04 & -0.41 \\
\hline Country of origin & 3.57 & 1.73 & .17 & $2.06^{*}$ \\
\hline Group membership & -0.61 & 1.44 & -.03 & -0.42 \\
\hline Years with armed group & $<0.01$ & $<0.01$ & .06 & 0.56 \\
\hline \multicolumn{5}{|l|}{ Step 2} \\
\hline Age & -0.27 & 0.15 & -.19 & -1.64 \\
\hline Joining as a child & -1.49 & 1.64 & -.04 & -0.50 \\
\hline Country of origin & 4.34 & 1.69 & .20 & $2.44 *$ \\
\hline Group membership & 0.86 & 1.47 & .03 & 0.40 \\
\hline Years with armed group & $<0.01$ & $<0.01$ & .04 & 0.36 \\
\hline Perpetrated violence types & 0.75 & 0.38 & .16 & $1.98 *$ \\
\hline Experienced violence types & 1.55 & 0.66 & .19 & $2.35 *$ \\
\hline Recruitment type $^{\mathrm{a}}$ & -2.14 & 1.31 & -.12 & -1.63 \\
\hline \multicolumn{5}{|l|}{ Step 3} \\
\hline Age & -0.27 & 0.15 & -.21 & -1.82 \\
\hline Joining & -1.48 & 1.66 & -.08 & -0.91 \\
\hline Country of origin & 4.34 & 1.68 & .21 & $2.59 *$ \\
\hline Group membership & 0.86 & 1.47 & .05 & 0.59 \\
\hline Years with armed group & $<0.01$ & $<0.01$ & .04 & 0.37 \\
\hline Perpetrated violence types & 1.56 & 0.51 & .33 & $3.07 * *$ \\
\hline Experienced violence types & 0.34 & 0.88 & .04 & 0.38 \\
\hline Recruitment type ${ }^{a}$ & -2.10 & 1.30 & -.12 & -1.63 \\
\hline $\begin{array}{l}\text { Experienced Violence Types } \\
\times \text { Recruitment Type }\end{array}$ & 2.56 & 1.25 & .21 & $2.05^{*}$ \\
\hline $\begin{array}{l}\text { Perpetrated Violence Types } \times \\
\text { Recruitment Type }\end{array}$ & -0.03 & 0.75 & -.24 & $-2.31 *$ \\
\hline
\end{tabular}

Note. $N=202 ; R^{2}=.20 . \mathrm{SE}=$ standard error.

${ }^{a}$ Forcibly recruited combatants were used as the reference group.

$* p<.05$. ** $p<.01$. *** $p<.001$.

of the number of experienced violence types $\left(\eta^{2}<.01\right)$ and of the PSS-I score $\left(\eta^{2}=.02\right)$, however, did not differ significantly between forcibly recruited and voluntary combatants (see Table 1).

\section{Predictors of PTSD Symptom Severity}

The first regression model with only the control variables of age, length of time with armed group, group membership, country of origin, and joining as a child accounted for $7 \%$ of the variability of the PSS-I score, $R^{2}=.09, F(5,198)=4.03, p=.002$. After adding number of experienced and perpetrated violence types as well as the recruitment type, the regression model accounted for $14 \%$ of the variance. The change in $R^{2}$ was significant, $\Delta R^{2}=.08, F(3,195)=6.22, p<.001$. As shown in Table 2 , the main effects of number of perpetrated violence types and of number of self-experienced violence types were positively related to the PSS-I score. The main effect of the recruitment type, however, did not predict the PSS-I score significantly.

The third regression model, including also the two-way interactions between the group variable, recruitment type, and both number of self-experienced and perpetrated violence types, explained $16 \%$ of the variability of the PSS-I score. The change in $R^{2}$ was significant, $\Delta R^{2}=.03, F(2,193)=3.12, p=.046$. Adding the three-way interaction did not improve the model, $\Delta R^{2}<.01, F(1,192)<0.01, p=.951$. As shown in Table 2, both two-interaction terms were significant. The interaction between number of self-experienced violence types and recruitment type correlated positively and the interaction between perpetrated violence types and recruitment type negatively with the PSS-I score.

A subsequent regression analysis, which was performed separately for both groups, revealed that experienced violence types were only related positively to the PSS-I score in voluntary combatants $(\beta=.31, t=2.78, p=.006)$. Moreover, perpetrated violence types correlated only positively with the PSS-I score in forcibly recruited combatants $(\beta=.39, t=3.32$, $p=.001)$.

\section{Discussion}

Results showed that voluntary combatants reported more perpetrated violence types and a higher level of appetitive aggression than combatants who were forcibly recruited. These findings are in accordance with prior research concerning child soldiers and combatants in the DRC. As expected, no differences were found between forcibly recruited and voluntary combatants concerning exposure to violence. This was also true, however, for PTSD symptom severity. One might expect lower PTSD symptom severity in voluntary combatants, as they showed higher levels of appetitive aggression. Appetitive aggression is thought to buffer or to prevent PTSD. This seems only to be the case, however, if combatants do not exceed a certain threshold of self-experienced traumatic events (Elbert et al., 2010). Yet this might apply in the present study as all participants experienced a high number of violent acts as well as other traumatic events. Further research is needed to clarify the link between appetitive aggression and PTSD symptom severity.

Furthermore, results indicated that the recruitment type influences the correlation of both self-experienced and perpetrated violence with PTSD symptom severity. Consistent with MacNair (2001, 2002), we found a positive relation between PTSD symptom severity and perpetrated violence. This, however, was only true for forcibly recruited combatants. For these combatants, perpetrating violence seems to be more aversive than experiencing violence. Being forced to carry out cruel forms of violence (e.g., against their own village or ethnic group) might explain this. In concordance with prior research, we also found a positive relationship between self-experienced violence and PTSD symptom severity. Surprisingly, only voluntary but not forcibly recruited combatants showed this relationship. As all forcibly recruited combatants in the current study experienced extreme forms of violence and survived years 
in very violent environments, the variability of the number of experienced violence types is limited. The current study, however, cannot determine whether the lack of a relationship between self-experienced violence and PTSD symptom severity in forcibly recruited combatants is a result of a limited variance in this extreme group. Future studies need to investigate and replicate these findings.

Consistent with prior findings, voluntary combatants reported high levels of appetitive aggression. These results are in accord with the notion that they perceived perpetrating violence not necessarily as traumatic but rather as fascinating and appealing. Our study furthermore shows that in contrast to forcibly recruited combatants, voluntary combatants showed no correlation between perpetrated violence and PTSD symptom severity. Although both groups had comparable levels of PTSD symptom severity, in voluntary combatants it was specifically self-experienced violence and not perpetrated violence that was positively correlated with PTSD symptom severity.

Consequently, it is important not to value perpetrating violence intrinsically as traumatic as is commonly done in a number of studies. In fact, the results of the present study indicate that perpetrating violence is traumatic for many, however, not for all combatants. Whether perpetrating violence is traumatic seems to depend on the perception of violence. In the present study, voluntary combatants perceived violence as fascinating and appealing.

The degree to which the results of the present study can be generalized is limited. First, the cross-sectional study design and the specific sample would not allow establishing causality. Although we interviewed all ex-combatants who were enrolled in the program of the United Nations and a Congolese organization at the time of assessment, the sample was probably not representative for (ex-)combatants in the DRC. Not all excombatants are enrolled in a program and the sample consisted mainly of deserted combatants, who might not be comparable to active combatants.

Although we tried to rate the combatant's own perception of his recruitment, in some cases the decision to join was the result of limited choices in a resource-poor region of instability. This sometimes blurred the boundaries between forcible and voluntary recruitment and might have influenced the results of the present study. Nevertheless, we hold that voluntary combatants feel more in control of their lives and perceive the armed group as less threatening than forcibly recruited combatants.

The present study only differentiated between foreign and local armed groups. Combatants from different local armed groups, however, were interviewed. Although the different local armed groups did not differ obviously, for example concerning reported levels of aggression or perpetrated violence, minor differences might influence the results. The same might be true for different interview places. The ex-combatants talked openly about perpetrating violence and appetitive aggression. Generally, the respondents appreciated very much the possibility to detail the situation in the eastern Congo and their own experi- ences. A potential bias, like an influence of social desirability, however, can never be ruled out for subjective reports.

Future research should investigate the causal relation between perpetrated violence and mental ill health more closely. The moderating effects of recruitment type and appetitive aggression also need further clarification. Additionally, the role of guilt as an important variable for development and maintenance of PTSD (Henning \& Frueh, 1997; Lee, Scragg, \& Turner, 2001) should be investigated. This is because guilt might explain the different impact of perpetrating violence on PTSD between forcibly recruited and voluntary combatants.

All in all, the results of the present study indicate that perpetrating violence is positively related to trauma-related mental illness in many, but not all, combatants. As a consequence, we cannot consider perpetrating violence intrinsically as traumatic. In fact, it is very important to consider the combatant's perception of violence. The same situation might be traumatic for one but appealing for the other.

\section{References}

American Psychiatric Association. (2000). Diagnostic and statistical manual of mental disorders (4 ed., text rev.). Washington, DC: American Psychiatric Association.

Amone-P'Olak, K., Garnefski, N., \& Kraaij, V. (2007). The impact of war experiences and physical abuse on formerly abducted boys in northern Uganda. South African Psychiatry Review, 10, 76-82.

Bayer, C. P., Klasen, F., \& Adam, H. (2007). Association of trauma and PTSD symptoms with openness to reconciliation and feelings of revenge among former Ugandan and Congolese child soldiers. The Journal of the American Medical Association, 298, 555-559. doi:10.1001/jama.298.5.555

Catani, C., Jacob, N., Schauer, E., Kohila, M., \& Neuner, F. (2008). Family violence, war, and natural disasters: A study of the effect of extreme stress on children's mental health in Sri Lanka. BMC Psychiatry, 8, 33. doi: $10.1186 / 1471-244 X-8-33$

Coalition to Stop the Use of Child Soldiers. (2010). Mai Mai child soldier recruitment and use: Entrenched and unending (pp. 1-17). London, England: Coalition to Stop the Use of Child Soldiers.

Davis, L., \& Hayner, P. (2009). Difficult peace, limited justice: Ten years of peacemaking in the DRC. Prospects (pp. 1-44). New York: International Center for Transitional Justice.

Elbert, T., \& Schauer, M. (2002). Burnt into memory. Nature, 419, 883. doi: $10.1038 / 419883 a$

Elbert, T., Weierstall, R., \& Schauer, M. (2010). Fascination violence: On mind and brain of man hunters. European Archives of Psychiatry and Clinical Neuroscience, 260, 100-105. doi:10.1007/s00406-010-0144-8

Ertl, V., Pfeiffer, A., Saile, R., Schauer, E., Elbert, T., \& Neuner, F. (2010). Validation of a mental health assessment in an African conflict population. Psychological Assessment, 22, 318-324. doi:10.1037/a0018810

Foa, E. B., Cashman, L., Jaycox, L., \& Perry, K. (1997). The validation of a self-report measure of posttraumatic stress disorder: The Posttraumatic Diagnostic Scale. Psychological Assessment, 9, 445-451. doi:10.1037//10403590.9 .4 .445

Foa, E. B., Riggs, D. S., Dancu, C. V., \& Rothbaum, B. O. (1993). Reliability and validity of a brief instrument for assessing post-traumatic stress disorder. Journal of Traumatic Stress, 6, 459-473. doi:10.1007/BF00974317 
Foa, E, B., \& Tolin, D. F (2000). Comparison of the PTSD Symptom ScaleInterview Version and the Clinician-Administered PTSD scale. Journal of Traumatic Stress, 13, 181-191. doi:10.1023/A:1007781909213

Guy, K. M. (2009). The political and cultural background for using child soldiers. Torture, 19, 132-136.

Hecker, T., Hermenau, K., Maedl, A., Elbert, T., \& Schauer, M. (2012). Appetitive aggression in former combatants-derived from the ongoing conflic in DR Congo. International Journal of Law and Psychiatry, 35, 244-249. doi:10.1016/j.ijlp.2012.02.016

Henning, K. R., \& Frueh, B. C. (1997). Combat guilt and it relationship to PTSD symptoms. Journal of Clinical Psychology, 53, 801-808. doi:10.1002/(SICI) 1097-4679(199712)53:8<801::AID JCLP3 $>3.0 . \mathrm{CO} ; 2-\mathrm{I}$

Hermenau, K., Hecker, T., Maedl, A., Schauer, M., \& Elbert, T. (2012) Growing up in armed groups: trauma and violence pose challenges for the integration of child soldiers into civil society. Manuscript submitted for publication.

Hermenau, K., Hecker, T., Ruf, M., Schauer, E., Elbert, T., \& Schauer, M. (2011). Childhood adversity, mental ill-health and aggressive behavior in an African orphanage: Changes in response to trauma-focused therapy and the implementation of a new instructional system. Child and Adolescent Psychiatry and Mental Health, 5, 29. doi:10.1186/1753-2000 5-29

Kleinbaum, D. G., Kupper, L. L., Nizam, A., \& Muller, K. E. (2008). Applied regression analysis and other multivariable methods (4th ed.). Belmont, CA: Thomson Brooks/Cole.

Kolassa, I.-T., \& Elbert, T. (2007). Structural and functional neuroplasticity in relation to traumatic stress. Current Directions in Psychological Science 16, 321-325. doi:10.1111/j.1467-8721.2007.00529.x

Lee, D. A., Scragg, P., \& Turner, S. (2001). The role of shame and guilt in traumatic events: the clinical model of shame-based and guiltbased PTSD. British Journal of Medical Psychology, 47, 451-466. doi: $10.1348 / 000711201161109$

MacNair, R. M. (2001). Psychological reverberations for the killers: Preliminary historical evidence for perpetration-induced traumatic stress. Journal of Genocide Research, 3, 273-282. doi:10.1080/14623520120062457

MacNair, R. M. (2002). Perpetration-induced traumatic stress in combat veterans. Peace and Conflict: Journal of Peace Psychology, 8, 63-72. doi:10.1207/S15327949PAC0801_6

Maedl, A. (2011). Rape as weapon of war in the eastern DRC? The victims' perspective. Human Rights Quarterly, 33, 128-147. doi:10.1353/hrq.2011.0005

McNally, R. J. (2006). Cognitive abnormalities in post-traumatic stress disorder. Trends in Cognitive Sciences, 10, 271-277. doi:10.1016/j.tics.2006.04.007

Neuner, F., Schauer, M., Karunakara, U., Klaschik, C., Robert, C., \& Elbert, T. (2004). Psychological trauma and evidence for enhanced vulnerability for posttraumatic stress disorder through previous trauma among West Nile refugees. BMC Psychiatry, 4, 34. doi:10.1186/1471-244X-4-34
Odenwald, M. Hinkel, H. Schauer, E., Neuner, F, Schauer, M., Elbert, T., \& Rockstroh, B. (2007). The consumption of khat and other drugs in Somali combatants: A cross-sectional study. PLoS Medicine, 4, e341. doi:10.1371/journal.pmed.0040341

Pfeiffer, A., \& Elbert, T. (2011). PTSD, depression and anxiety among former abductees in Northern Uganda. Conflict and Health, 5, 14. doi:10.1186/1752-1505-5-14

Pham, P. N., Vinck, P., \& Stover, E. (2009). Returning home: Forced conscription, reintegration, and mental health status of former abductees of the Lord's Resistance Army in northern Uganda. BMC Psychiatry, 9, 23. doi: $10.1186 / 1471-244 X-9-23$

Romkema, H. (2007). Opportunities and constraints for the disarmament \& repatriation of foreign armed groups in the Democratic Republic of Congo. Washington, DC: The World Bank.

Schauer, E., \& Elbert, T. (2010). The psychological impact of child soldiering. In E. Martz (Ed.), Trauma rehabilitation after war and conflict (pp. 311 360). New York: Springer New York. doi:10.1007/978-1-4419-5722-1

Tabachnick, B. G., \& Fidell, L. S. (2006). Using multivariate statistics (5th ed.). New York: Pearson Education.

Vinck, P., Pham, P. N., Stover, E., \& Weinstein, H. M. (2007). Exposure to war crimes and implications for peace building in northern Uganda. The Journal of the American Medical Association, 298, 543-554. doi:10.1001/jama.298.5.543

Vitiello, B., \& Stoff, D. M. (1997). Subtypes of aggression and their relevance to child psychiatry. Journal of the American Academy of Child and Adolescent Psychiatry, 36, 307-315. doi:10.1097/00004583-199703000-00008

Waller, J. (2006). Becoming evil: How ordinary people commit genocide and mass killing. In M. Fitzduff \& C. E. Stout (Eds.), The psychology of resolving global conflicts: From war to peace. Nature vs. nurture (1st ed., pp. 89-107). Westport, CT: Praeger Security International.

Weierstall, R., \& Elbert, T. (2011). The Appetitive Aggression Scaledevelopment of an instrument for the assessment of human attraction to violence. European Journal of Psychotraumatology, 2, 8430. doi: $10.3402 /$ ejpt.v2i0.8430

Weierstall, R., Schaal, S., Schalinski, I., Dusingizemungu, J.-P., \& Elbert, T. (2011). The thrill of being violent as an antidote to posttraumatic stress disorder in Rwandese genocide perpetrators. European Journal of Psychotraumatology, 2, 6345. doi:10.3402/ejpt.v2i0.6345

Weierstall, R., Schalinski, I., Crombach, A., Hecker, T., \& Elbert, T. (2012). When combat prevents PTSD symptoms - results from a survey with former child soldiers in Northern Uganda. BMC Psychiatry, 12, 41 doi: $10.1186 / 1471-244 X-12-41$

Weierstall, R., van der Haer, R., Banholzer, L., \& Elbert, T. (2012). Becoming cruel-appetitive aggression released by detrimental socialisation in former Congolese soldiers. Manuscript submitted for publication.

World Health Organization. (2008). Multiaxial class child \& adol psych: The ICD-10 Classification of Mental and Behavioural Disorders in Children and Adolescents. Cambridge, England: Cambridge University Press. 